\title{
Older People, Time Use, and Multigenerational Families in East Asia
}

\author{
Man-Yee Kan ${ }^{1} \cdot$ Kamila Kolpashnikova ${ }^{1}$
}

Published online: 25 November 2021

() The Author(s), under exclusive licence to Springer Nature B.V. 2021

This special issue features five papers about older people and their family members in East Asian countries. The population in East Asia and the rest of the world is aging precipitously. In Japan, people aged 65 or over account for $17.4 \%$ of the total population in 2000, and the figure reached $22.8 \%$ in 2010 and $28.8 \%$ in 2020 . In Korea, the corresponding figures were $7.2 \%, 10.8 \%$ and $15.7 \%$. In China, the corresponding figures were $6.8 \%, 8.1 \%$ and $12.0 \%$ (OECD, 2021). It is common for older people to reside with their adult children in East Asia. In Asia, living with a child or with extended family members is the most common form of living arrangement among people aged 65 years or over (United Nations, 2019). Furthermore, increases in life expectancy imply that older people are playing an increasingly important role in their adult children's daily lives. Older people can provide care and domestic support to the family, thereby potentially relieving work-life conflicts of their adult children. On the other hand, they may need care and support themselves.

The first paper of this special issue focuses on the daily schedules of women caregivers in Japan. In Eldercare in Japan: Cluster Analysis of Daily Time-Use Patterns of Elder Caregivers, Kolpashnikova and Kan explore the challenges that women-caregivers face in the increased burden of unpaid work that they do daily. They identify the unique patterns of daily time-use for co-resident caregivers. This paper contributes to the academic discussion on time poverty among caregivers and gender inequality in caregiving. It extends previous work on caregiver time-use patterns by differentiating between leisure and paid work activities and analysing daily patterns by weekdays and weekends.

The second and the third papers investigate how grandparents may affect the parenting practices and childcare time of their adult children. In The Effect of Grandparental Care on Men's and Women's Parenting Practices in Taiwan, Tai and Tu explore how grandparental help in childcare affects the parenting practices of adults

Man-Yee Kan

man-yee.kan@sociology.ox.ac.uk

Kamila Kolpashnikova

kamila.kolpashnikova@sociology.ox.ac.uk

1 University of Oxford, Oxford, UK 
in Taiwan. They show that when their own parents assist with childcare, fathers and mothers are likely to adopt a more authoritative style of child-rearing and apply more disciplinary practices. However, when in-laws are helping with childcare, mothers are likely to adopt less authoritative styles of parenting. The results demonstrate differential effects on mothers' parenting practices in multigenerational living arrangements.

In Family Dynamics of Child Care in Korea: Strategies to Relieving the Gap Between Mother's Actual and Preferred Hours of Care, Cha and Eun analyse the gap between mothers' actual and preferred hours of childcare in South Korea. They show that although both working and non-working mothers spend more time on childcare than they would wish to, the gap between actual and preferred time is lower if there is some help from grandparents, both in resources and time. Yet, the results also show that mothers rely heavily on household income or their own income if help from friends and relatives is unavailable. The paper raises an argument for more financial support of mothers in the form of additional family allowance to reduce the gap.

The fourth paper finds strong gendered patterns in the associations between coresidence with older parents and adult children's time use. In Married Adults Coresiding with Older Parents: Implications for Paid Work and Domestic Work Loads, Hertog and Kan find coresidence with older parents is strongly associated with working-age women's, but not working-age men's, time spent on paid work, housework, childcare, and adult care. Coresidence with older parents is genderally associated with longer paid work time and shorter housework and childcare time for working age women. Furthermore, older mothers provide more help in childcare and housework than older fathers.

The last paper provides an overview of time use patterns of older people across both East Asian (China, Japan, South Korea and Taiwan) and European and Anglophone countries (Canada, Denmark, Finland, France, Italy, the Netherlands, Norway, Spain, United Kingdom, and United States). Gender and educational inequalities in time use continue at older ages but the gender gaps and educational gradients vary according to cultural contexts and welfare policies. In How do Older Adults Spend Their Time? Gender Gaps and Educational Gradients in Time Use in East Asian and Western Countries, Kan, Zhou, Negraia, Kolpashnikova, Hertog, Yoda and Jun examine how older people in East Asian and Western countries spend their time on paid work, domestic work, leisure, and sleep between 2000 and 2015. In most of the countries, women spend more time on domestic work, less time on paid work, and leisure. However, the gender gaps are larger in the East Asian countries. Higher levels of educational attainment are associated with less time on paid work, more time on leisure, and less time on sleep in the East Asian countries, but in most of the Western countries they are associated with more paid work, less domestic work, and less sleep.

Acknowledgements The papers of this special issue were presented at the conference "Multigenerational Families in East Asia" on $10^{\text {th }}$ and $11^{\text {th }}$ January 2020 at University of Oxford, UK. We gratefully acknowledge the financial support from the European Research Council Consolidator Grant agreement 
No. 771736 (awardee: Man-Yee Kan), and the Economic and Social Research Council Grant No. ES/ S014098/1 (PI: Man-Yee Kan), the Marie Sklodowska-Curie grant agreement No 892101 (awardee: Kamila Kolpashnikova), the John Fell Fund of the University of Oxford No 7609 (awardee: Kamila Kolpashnikova), and the JSPS London Symposium and Seminar Scheme Grant (awardee: Ekaterina Hertog).

\section{References}

OECD (2021). Elderly population (indicator). https://doi.org/10.1787/8d805ea1-en (Accessed on 10 November 2021).

United Nations (2019). Living arrangement of older persons around the world. (2019/2). United Nations Retrieved from https://www.un.org/en/development/desa/population/publications/pdf/popfacts/ PopFacts_2019-2.pdf.

Publisher's Note Springer Nature remains neutral with regard to jurisdictional claims in published maps and institutional affiliations. 